\title{
Applying the workload indicators of staffing needs method in nursing health workforce planning: evidences from four hospitals in Vietnam
}

\author{
Thu Thi Hoai Nguyen ${ }^{1}$, Hung Thanh Phung ${ }^{1}$ and Anh Thi My Bui $2^{*^{*}}$ (D)
}

\begin{abstract}
Background: Vietnam has encountered difficulties in ensuring an adequate and equitable distribution of health workforce. The traditional staffing norms stated in the Circular 08/TT-BYT issued in 2007 based solely on population or institutional size and do not adequately take into consideration the variations of need such as population density, mortality and morbidity patterns. To address this problem, more rigorous approaches are needed to determine the number of personnel in health facilities. One such approach is Workload Indicators of Staffing Need (WISN) developed by the World Health Organization (WHO), a facility-based workforce planning method that assists managers in defining the responsibilities of different workforce categories and improving the appropriateness and efficiency of a staff mix.

Methods: This study applied the WISN approach and was employed in 22 clinical departments at four hospitals in Vietnam between 2015 and 2018. 22 targeted group discussions involving nurses were conducted. Hospital personnel records have been retrieved. The data were analyzed according to WISN instructions.

Results: Of the 22 departments, there was a shortage of 1 to 2 nurses in 10 departments, with WISN ratios ranging between 0.88 and 0.95 . Only 01 clinical colleges at Can Tho Hospital lacked 05 nurses, facing a high workload with a WISN ratio of 0.78 . Administrative time represented $20-40 \%$ of the total work time of a nurse. In comparison, nurses at Can Tho Hospital spent time on administration from 24 onwards. 5-41.7\% of their working time while nurses at Thanh Hoa Hospital spent $21-33 \%$.

Conclusions: The application of the WISN enabled health managers to analyze the workload of nurses, calculate staffing needs, and thus effectively contribute to the workforce planning process. It is expected that the results of this research will encourage the use of the WISN tool in other hospitals and health facilities across the health system. At provincial and national levels, this study provides important evidence to help policy makers develop guidelines for personnel norms for health facilities in the context of limited resources, while the existing regulation is no longer appropriate.
\end{abstract}

Keywords: Workload Indicators of Staffing Need, WISN, Nursing workforce, Human resource for health, Vietnam

\footnotetext{
*Correspondence: myanhbui@gmail.com

${ }^{2}$ Department of Hospital Management, Health Management Training Institute, Hanoi University of Public Health, 1A Duc Thang Road, Duc Thang Ward, North Tu Liem District, 10000 Hanoi, Vietnam

Full list of author information is available at the end of the article
}

\section{Background}

According to the health care framework of the six building-blocks of the World Health Organization (WHO) [1], human resources play an important role in providing original author(s) and the source, provide a link to the Creative Commons licence, and indicate if changes were made. The images or other third party material in this article are included in the article's Creative Commons licence, unless indicated otherwise in a credit line to the material. If material is not included in the article's Creative Commons licence and your intended use is not permitted by statutory regulation or exceeds the permitted use, you will need to obtain permission directly from the copyright holder. To view a copy of this licence, visit http://creativecommons.org/licenses/by/4.0/. The Creative Commons Public Domain Dedication waiver (http://creativeco mmons.org/publicdomain/zero/1.0/) applies to the data made available in this article, unless otherwise stated in a credit line to the data. 
and ensuring quality health services to the community, as well as is one of factors affecting the effectiveness and efficiency of health systems in country. Recently, the developing countries, particularly in low and middle income countries (LMICs) are facing the need for trained health-care staffs to meet with the increasing demand for quality health services that could led to a pressure on managers in effectively allocating their human resources [2-5].

As a human resource to address health challenges, the World Health Organization developed the Staffing Needs Workload Indicators (WISN) in the late 1990s [4]. The advantages of the WISN method indicated in some studies that was the calculation basis on actual work that has made it a completely objective tool for determining the desirable level of human resources. In addition, the application of the WISN could lead to efficient use of resources and enhance the quality of services. $[5,6]$.

The WISN method has been used in practice in several developing countries to determine staffing requirements for multiple categories by level of care and geographic areas. In Uganda, for instance, the first WISN experiment was carried out for different categories of health staffs working in health facilities, then the second WISN application focused on nurses, and nursing assistants in a tertiary-level hospital. On the other hand, the WISN in Mozambique and Indonesia targeted maternal and child health workers, midwives, clinicians and nurses in rural and urban hospitals or health centers [7]. The WISN application has contributed to appropriate evidencebased health workforce policy development, planning and management. WISN has been useful for health care managers in the staffing decision-making process; determining the required number of specific type health staff for health services in each facility; estimating work pressure on health workers; and reallocating or managing the transfer of functions-transferring and sharing tasks; planning for future staffing of health care service delivery based on anticipated workload of health facilities $[5,8]$.

Vietnam has struggled to ensure an appropriate and equitable distribution of the health workforce [9]. The traditional staffing standards set out in Circular 08/ TT-BYT released in 2007 [10] based solely on population or institutional size and does not adequately reflect changes in needs, such as population density, mortality and morbidity patterns. To solve this problem, it is necessary to seek more rigorous approaches to determining staffing levels in healthcare facilities. The main objective of this study is to assess and calculate the current workloads and staffing needs of nurses in 4 selected hospitals in Vietnam, using workload indicators of staffing needs. The WISN method is based on the work undertaken by health staffs (medical doctors and nurses) and is used in this context to estimate human resources availability for medical activities at the provincial hospital level.

\section{Methods \\ Study design}

The study applied the Workload Indicators of Staffing Need (WISN) manual [11]. The WISN method is a human resource tool for staffing planning and decision making that considers certain information in the calculation of staffing requirements for health care services and activities. The information requested includes the components of the workload (i.e. the common activities performed by a cadre on basic daily health services), the time of activities standards (i.e. the time it takes a cadre to perform their activities standards), the available working time (i.e. the available time in one year for a cadre to complete their work) and the annual workload statistic (i.e. the annual statistic of health services delivery in healthcare facility). Therefore, the study was used with the combination of quantitative and qualitative methods and secondary data retrieval to gather key data for the WISN calculation.

\section{Study sites}

The study was conducted from $01 / 2015$ to $12 / 2018$ in 4 provincial general hospitals in Bac Giang, Thanh Hoa (in the North of Vietnam) and Can Tho, Dong Thap (in the South of Vietnam).

\section{Object of research and data collection Phase 1}

Secondary data collection: the study used data collection checklist to collect hospital reports on personnel, hospital statistics in 2015-2016 (Bac Giang, Thanh Hoa hospitals), in 2017-2018 (Can Tho and Dong Thap hospitals).

\section{Phase 2}

Quantitative research The three-category-of-nurse (including clinical nurse, administrative nurse and pharmaceutical nurse) was identify in each department, 2 nurses in each category were selected in this phase. Total of 132 selected nurses in 22 clinical departments in 4 hospitals were interviewed about working hours and tasks, using a semi-structured questionnaire. The questionnaire was designed according to the WISN manual construction and focused on 3 workload components (i.e. clinical activities, administrative/ management activities and other activities (e.g. extracurricular activities, musical performance, youth and union activities in hospitals, etc.)

\section{Phase 3}

Qualitative research, the study conducted 22 focused group discussions (FGDs) with nurses working in 22 
selected faculties to identify and validate workload components, activity standards and time standard for performing specific activities. Each FGD included 5-6 nurses (head nurses, clinical nurses and administrative nurses).

\section{Data collection}

The study followed WHO guidelines on steps to apply the WISN toolkit [11]. To determine available working time (AWT), the study used a secondary data checklist to collect working hours for nurses in the previous year of the research year. To identify workload components, the study sent questionnaires to nurses of selected faculties, then organized FGDs and collected advices from health experts from Provincial Department of Health and stakeholders (hospital directors, head nurses, clinical nurses and administrative nurses) to identify and validate workload components (i.e. clinical activities, administration/ management activities and other activities. In particular, the clinical activities focused on 13 standard routine activities of nurses in internal medicine and surgery block in hospitals.

The FGDs were also at the aim to define activity standards. At all four hospitals, the research used an observational method to determine nursing activity standards. Each activity was observed a minimum of 10 times by head nurses and the research team to accurately estimate the duration of nursing activity standards.

The study also collected reports on the results of nursing activities during the year in order to calculate standard workloads, allowance factors and and total required number of staff based on WISN.

\section{Data analysis}

The quantitative data was checked and entered into the Excel software for analysis according to the instructions in the WISN toolkit.

\section{WISN technique and calculations}

According to WISN method, the required input for calculation of staffing requirements including the AWT, number of current staff, workload components, time of activity standards and annual workload of health services.

1) $\mathrm{AWT}=\mathrm{A}-(\mathrm{B}+\mathrm{C}+\mathrm{D}+\mathrm{E})$

In which: $A$ : the number of available working days in a year; $\mathrm{B}$ : the number of public holidays; $\mathrm{C}=$ the number of day-off due to annual leave; $\mathrm{D}=$ the number of day-off due to sickness; $\mathrm{E}=$ the number of day-off due to other leaves;

2) Activity standard (AS): Time necessary for a cadre to perform their standard activity. AS to calculate the standard workload, category allowance factor (CAF) and individual allowance factor (IAF).
Standard workload

$$
=\text { Available Working Time/ Activity Standard }
$$

(The activity standard was obtained through key informant interview with head nurses).

3) Category allowance factor (CAF): This was calculated by summing up the percentages of time it takes all members of the staff category to perform activities for which the annual statistics were not available known as category allowance standard (CAS). The CAF was calculated by using the formula: $\mathrm{CAF}=1 /(1-\Sigma \mathrm{CAS} \%)$.

4) Individual allowance factor (IAF) was used to derive the individual allowance factor using the formula: $\mathrm{IAF}=\mathrm{IAS} / \mathrm{AWT}$.

In which, individual allowance standard (IAS) was obtained by calculating how much time additional activities of certain cadre require.

5) Workload-Based Staffing Requirements: The results obtained from the above variables were then used to compute the workload-based staffing requirements using the formula:

\section{WISN staff requirement :}

\section{$=-[($ Annual workload $x$ CAF $) /$ Standard workload $]$ + IAF}

For qualitative data, all information from FGDs was transcribed and analyzed by content analysis techniques. The content was analyzed to provide comprehensive evidence and reconfirm nurse workload components and work standards.

\section{Ethical consideration}

The study was approved by the Institutional Review Board of the Hanoi University of Public Health (Approval number 017-173/DD-YTCC).

\section{Results}

Table 1 described general information of 04 selected hospitals. The research collected data at Bac Giang and Thanh Hoa general hospitals in 2015-2016, at Can Tho central hospital and Dong Thap general hospital in 20172018. There were 22 clinical faculties studied, including 11 faculties of surgery and 11 faculties of internal medicine. In general, the available working time (AWT) of hospitals ranged from $1850 \mathrm{~h}$ to $2000 \mathrm{~h}$ per year, varied by hospital due to the difference in number of days off of faculties. In Can Tho central hospital for instance, the AWT of nuses working in Neurology faculty was $1633 \mathrm{~h}$ because the nurses in this faculty are required to work $7 \mathrm{~h}$ per day.

The number of patients hospitalized annually at each faculty varied from hospital to hospital. In particular, the 
Table 1 General information of the selected hospitals

\begin{tabular}{|c|c|c|c|c|}
\hline \multirow[t]{3}{*}{ Year of research } & \multicolumn{4}{|c|}{ Provincial general hospital } \\
\hline & Bac Giang & Thanh Hoa & Can Tho & Dong Thap \\
\hline & 2015 & 2015 & 2017 & 2018 \\
\hline Number of faculty in research & 7 & 6 & 5 & 4 \\
\hline Surgery & 3 & 3 & 3 & 2 \\
\hline Internal medicine & 4 & 3 & 2 & 2 \\
\hline Available working time (AWT) (hours) & $1856-1988$ & $1976-2008$ & 1633-1989 & $1958-2021$ \\
\hline Number of inpatients in each faculty/year & $1545-5773$ & $2012-5845$ & $3478-7777$ & $1633-7003$ \\
\hline Number of nurses in each faculty & $11-21$ & $15-21$ & $16-23$ & $11-16$ \\
\hline Total number of inpatient treatment days & $18923-44739$ & $18139-49963$ & $15625-35455$ & $13560-63805$ \\
\hline
\end{tabular}

highest number of inpatients per year was recorded at Can Tho central hospital (from 3478 to 7777 inpatients) and at Dong Thap general hospitals (from 1633 to 7003 inpatients). In comparison, the range of inpatient number per year was lower than in Thanh Hoa hospital and Bac Giang hospital from 2012 to 5845 inpatients and from 1545 to 5773 , respectively. The number of nurses in each department also varied among hospitals. Can Tho central hospital has a largest number of nurses from 16 to 23 nurses, followed by Thanh Hoa hospital (15-21 nurses in each faculty) and Bac Giang hospital (11-21 nurses in each faculty). Otherwise, Dong Thap general hospital had a small number of nurses, from 11 to 16 nurses in each faculty. According to hospital statistics, the total number of inpatient treatment days in each faculty was highest in Dong Thap general hospital (from 13560 to 63805 days), meanwhile it reported only from 15625 to 35455 days for inpatient treatment in Can Tho central hospital.
Table 2 described the standards for nursing activities. The findings showed that the time allotted to the normal activity of each faculty in hospitals varied. For example, measuring survival indicators by a nurses working in Bac Giang and Thanh Hoa general hospitals was reported to take 5 min, however in Can Tho and Dong Thap general hospitals, this activity was completed in only $3 \mathrm{~min}$. Similarly in terms of standard time to perform intravenous injection, in Bac Giang and Thanh Hoa general hospitals nurses need $5 \mathrm{~min}$, more than those reported in Can Tho and Dong Thap general hospitals. Meanwhile, standard time of several activities in Can Tho, Dong Thap took longer than those in Bac Giang and Thanh Hoa general hospitals. For example, a standard time for blood transfusion by nurses in Bac Giang general hospital was $15 \mathrm{~min}$, in Thanh Hoa and Can Tho general hospitals was $30 \mathrm{~min}$; and from 30 to $40 \mathrm{~min}$ in Dong Thap general hospital. Even within a hospital, the standard time for performing an activity within the faculties was variable.

Table 2 Comparison of common standard activities of nurses for performing specialized services by hospitals

\begin{tabular}{|c|c|c|c|c|c|}
\hline \multirow[t]{2}{*}{ Activities } & \multirow[t]{2}{*}{ Unit } & \multicolumn{4}{|c|}{ Provincial general hospital } \\
\hline & & Bac Giang & Thanh Hoa & Can Tho & Dong Thap \\
\hline Monitoring patient with ICU levels & Mins/patient & $15 / 30$ & $15 / 20 / 30$ & $15 / 30$ & $15 / 30$ \\
\hline Medical procedures & Mins/patient & $30-100$ & $15 / 30$ & $5 / 30 / 120$ & $10 / 30 / 60$ \\
\hline Preparation of patients before and after surgery & Mins/patient & 30 & $25 / 30$ & $10 / 15 / 20$ & 10,15 \\
\hline Measuring survival indicators & Mins/time & 5 & 5 & 3 & 3 \\
\hline Taking additional blood & Mins/time & 5 & 3 & 5 & 5 \\
\hline Infusion/Transfusion & Mins/time & 5 & 5 & 6,7 & 7 \\
\hline Intravenous injection & Mins/time & 5 & 5 & $3-4$ & $3-4$ \\
\hline Intramuscular injection & Mins/time & 3 & 3 & 2 & 2 \\
\hline Subcutaneously injection & Mins/time & 3 & 2 & 2 & 2 \\
\hline Blood transfusion & Mins/time & 15 & 30 & 30 & $30 / 40$ \\
\hline Sonde fastrique & Mins/time & 5 & 5 & $5 / 6$ & $8-10$ \\
\hline Sonde Urinaire & Mins/time & 7 & 5 & $5-7$ & $8-10$ \\
\hline Dressing & Mins/time & 10 & 10 & $6-9$ & 8 \\
\hline
\end{tabular}


Table 3 The time spent to perform clinical services and administrative-management activities

\begin{tabular}{lllll}
\hline & \multicolumn{4}{l}{ Proportion of time allocated for clinical services and administrative/management activities } \\
\cline { 2 - 5 } & Bac Giang (\%) & Thanh Hoa (\%) & Can Tho (\%) & Dong Thap (\%) \\
\hline Clinical services & $63.2-74.4$ & $66.8-79.1$ & $61.3-75.5$ & $67.2-75.6$ \\
Administrative/ management activities, & $25.6-36.8$ & $20.9-33.2$ & $24.5-41.7$ & $24.4-32.8$ \\
Other activities & & & & \\
\hline
\end{tabular}

Table 3 describes the time spent on clinical services and administrative activities. The results showed that the time of administrative /management activities accounts for $20-40 \%$ of the total working time of a nurse. The faculties have different proportions of time for these activities. In comparion to other selected hospitals, nurses in Can Tho hospital spent the most time on administrative/ management activities, from 24.5 to $41.7 \%$ of their working time. Nurses in Thanh Hoa spent between 21 and $33 \%$ of their working time on administrative/management activities, including daily professional meetings in faculty, meeting of hospital, patient record completion, writing reports, etc.

Table 4 described the staff needs of the faculties following calculation using the WISN tool. The results showed that out of 22 clinical faculties in 04 general hospitals surveyed, 10 faculties had a shortage of nurses. The shortage of nurses was mainly occurred in the Internal Medicine faculties ( 7 faculties including 3 faculties at Bac Giang hospital (General medical, Cardiology, Gastroenterology), 2 faculties at Thanh Hoa hospital (General medical, Respiratory), 1 faculty at Can Tho hospital (General medical) and 2 faculties at Dong Thap hospital (General medical, Respiratory) whereas there were only 2 Surgical faculties (2 General Surgery faculties at Can Tho and Dong Thap hospital) did not have enough nurses. These understaffed faculties should be completed between 01 and 02 nurses each. Workload pressures in these faculties were not significant, with WISN ratios ranging from 0.88 to 0.95 .

A single clinical faculty at Can Tho general hospital lacked 05 nurses, facing a high workload with a WISN ratio of 0.78 . Three of the 22 faculties had enough staff, including 01 in internal medicine and 2 in surgery. The number of overstaffed faculties was 09 faculties, including 07 Surgical faculties and 2 Internal medicine faculties, with the excess number of nurses ranging from 01 to 03, depending on the faculties. Thus, we could see that if the shortage of nurses occurred mainly in the faculties of internal medicine, the excess of nurses often ended up in the faculties of surgery. Dong Thap general hospital did not have adequate number of staffs in almost clinical faculties, while at Thanh Hoa Hospital general hosptial, $2 / 3$ of the clinical faculties (equivalent to 4 faculties) had excess human resources.

\section{Discussion}

The aim of the study was to assess and calculate the current workloads and staffing needs of nurses in 4 selected hospitals and provide lessons learnt for application of WISN in the limited-resource context such Vietnam. There were 10 faculties among 22 faculties lacked of

Table 4 Required number of nursing staff based on WISN and WISN ratio

\begin{tabular}{|c|c|c|c|c|}
\hline & \multicolumn{4}{|c|}{ Provincial general hospital } \\
\hline & Bac Giang & Thanh Hoa & Can Tho & Dong Thap \\
\hline Number of understaffed faculties & 3 & 2 & 2 & 3 \\
\hline Internal medicine & 3 & 2 & 1 & 2 \\
\hline Surgery & 0 & 0 & 1 & 1 \\
\hline Shortage in understaffed faculties & $1-2$ & 0 & $2 / 5$ & 1 \\
\hline WISN ratio in understaffed faculties & $0.88-0.95$ & $0.88-0.95$ & $0.78-0.92$ & $0.91-0.92$ \\
\hline Number of adequate staffed faculties & 1 & 0 & 1 & 1 \\
\hline Internal medicine & 0 & 0 & 1 & 0 \\
\hline Surgery & 1 & 0 & 0 & 1 \\
\hline Number of overstaffed faculties & 3 & 4 & 2 & 0 \\
\hline Internal medicine & 1 & 1 & 0 & 0 \\
\hline Surgery & 2 & 3 & 2 & 0 \\
\hline Excess in overstaffed faculties & $1 / 3$ & $2 / 3$ & 2 & - \\
\hline
\end{tabular}


nurses, the mainly shortage of nurses occurred in the Internal Medicine faculties (with 07 faculties) whereas only 2 Surgical faculties have inadequate nurses. These understaffed faculties should be completed between 01 and 02 nurses each.

In this study, by selecting the same level hospitals (provincial level) and by selecting faculties in the Surgical and Internal Medicine block, we can use the results to compare the available and needed staff of faculties with the same specialization among hospitals by looking at the standard time for performing specific activities across the faculties within one hospital and across the selected hospitals. The findings showed that the AWT of hospitals ranges from 1850 to $2000 \mathrm{~h}$ per year, varies by hospital due to the difference in number of days off of faculties. The results showed that there was a substantial difference in the hours worked by nurses between hospitals and between the departments of the same hospital. The AWT of medical staff in Vietnam differs from other Africa countries. In some hospitals in Uganda, for example, the hours available for medical staff ranged between 1624 and 1688, or between 1825.4 and 1850 [12]. In fact, according to the number of the Labor Code 2012 (issued according to Decree 106/2012 dated 20/12/2012) [13], public servants, public service employees, work $8 \mathrm{~h}$ and 5 days per week, so every week has $40 \mathrm{~h}$ of work. However, in many faculties due to the great work pressure, staff often have to go half an hour earlier and go back home half an hour late to finish the job.

The proportion of time that nurses spend on clinical and administrative services varies between hospitals and faculties. The findings showed that administrative/management time represents $20-40 \%$ of a nurse's total work time. The outcome also revealed to the real context in hospitals that this is a waste or misuse of valuable nursing time. While nurses are trained in patient care, in fact, many are entrusted with activities other than care (e.g. paper working, medical records preparation, completion of transfer or discharge procedures in hospital). Our findings mirros the result from previous study in Nigeria [5], Indonesia [14] to indicate that the review of practice in health workforce should be implemented to ensure that the scope of practice of cadres match the specific training and skills and those are used in delivery of quality health services.

In this study we found that most faculties have two cadres of nursing staff, including caregiver (provide patient care) and administrative nurse (doing task of paying, and receiving and distributing drugs). The results show that some faculties are short of nursing staff, but, during this time, the work of administrative nurses is relatively light, with little or no pressure. As a result, time allocated to clinical services accounted for two-thirds of nurses' working time compared to time spent on administrative activities. As a result, the conclusion suggested that the review of the distribution of tasks in each faculty within the hospital should be implemented on a regular basis to ensure the efficient use of human resources. This study with WISN approach also helps managers to consider the consequences of human resource shortages, such as the quality of the medical service. When the WISN rate is high, it poses a difficult question to the manager to see if there is a staff shortage or if performance standards are problematic.

The recent Nigerian study also suggested examining scopes of practice to ensure that managers have the capacity to deliver quality service [5]. Furthermore, the standardization of professional and administrative activities, as well as the time needed to perform specific activities, should be reviewed. This would facilitate the proper distribution of tasks among managers that take into account skills, shortages and the inequitable distribution of the health workforce and current workload among the hospital faculties [15].

The WISN application obviously helps hospital managers to identify the lack or excess of human resources in the faculties, as well as to demonstrate executives with the strongest pressure; and maybe even come up with more suitable and effective human rearrangement solutions; and perhaps even find more appropriate and efficient human rearranging solutions. Based on these findings, the Can Tho central hospital, for example, provides an evidence base for decision-making in the reorganization and planning for the future recruitment of nurses to the hospital.

Our findings informed decision by the health policy makers to consider the current traditional staffing norms stated in the Circular 08/TT-BYT issued in 2007 [10] in which the staffing norms are applied to all hospitals of different levels (central-provincial-district) and merely based on the number of beds regardless other important factors such as population density, mortality and morbidity patterns with limited consideration to the characteristics of each faculty and hospital. The results from our study showed that the staffing need of faculties within one hospital and among hospitals are varied depending on the organization of work and task distribution in each faculty. The application of WISN therefore is recommended to scale up conduct of WISN study in more provinces across the country and encourage health managers and leaders to apply WISN as a national strategy for efficient health workforce planning.

\section{Limitation of the study}

One of the limitations of this study is to simply predict and plan the need for clinical nurses in four selected 
hospitals. The study was carried out on the nursing framework in the departments of internal medicine and surgery of 4 provincial hospitals, so the generalization to other hospitals may be limited. These results should be applied with caution, as staff organization and assignment may vary from hospital to hospital. The application of WISN in different types of clinical services in a greater number of hospitals requires further study. The workload of nurses in charge of receiving and distributing drugs to patients and perform hospital discharge payments has not been accurately calculated, while in each faculty, there are an average of 3-4 nurses working in this position. The assessment of staff workload and the calculation of staff needs depend greatly on the availability and accuracy of existing data. For departments that have an adequate archiving or reporting system, this will be an obstacle to implementing WISN. Poor documentation of health services data at the institutional level has led to overestimation or underestimation of the staffing requirements of some health facilities.

\section{Conclusions}

When applying WISN calculation, the study indicated that 10 among 22 faculties lacking from 1-2 nurses, the workload pressures in these faculties are not high with the WISN ratios are ranging from 0.88 to 0.95 . Only 01 faculty of internal medicine from Can Tho Central Hospital lacks 05 nurses, facing a high workload with a WISN ratio of 0.78 . It can be seen that the application of WISN has enabled health managers to analyze the workload of their cadres, calculate staffing needs, and thus effectively contribute to the workforce planning process. This study contributed to provide important evidence to help policy makers develop guidelines for personnel norms for health facilities in the context of limited resources, while the existing regulation Circular 08/TT-BYT since 2007 is no longer appropriate in Vietnam.

\section{Abbreviations}

AS: Activity Standard; AWT: Available Working Time; CAF: Category Allowance Factor; CAS: Category Allowance Standard; FGD: Focused Group Discussion; IAF: Individual Allowance Factor; IAS: Individual Allowance Standard; LMICS: Low and Middle Income Countries; WHO: World Health Organization; WISN: Workload Indicators of Staffing Need.

\section{Supplementary Information}

The online version contains supplementary material available at https://doi. org/10.1186/s12960-021-00668-y.

Additional file 1. WISN dataset at four Vietnam hospitals.

\section{Acknowledgements}

We are grateful to the study participants who agreed to be interviewed and provide information related to health workforce in 4 hospitals in Bac Giang,

Thanh Hoa, Can Tho and Dong Thap provinces.

\section{About this supplement}

This article has been published as part of Human Resources for Health Volume 19, Supplement 1 2021: Countries' experiences on implementing WISN methodology for health workforce planning and estimation. The full contents of the supplement are available at https://human-resourceshealth.biomedcentral. com/articles/supplements/volume-19-supplement-1.

\section{Authors' contributions}

All authors contributed to the study design and conducted data collection and analysis. PTH and NTHT prepared the first draft of this paper. NTHT and BTMA contributed and commented on the drafts. All authors read and approved the final manuscript.

\section{Funding}

This manuscript has submitted to the supplement "Workload Indicators for Staffing Need (WISN) methodology for health workforce planning and estimation" in HRH Journal that sponsored and coordinated by the World Health Organization.

Availability of data and materials

Data and materials are available on request.

\section{Declarations}

Ethics approval and consent to participate

This research was approved by Institutional Review Board of Hanoi University of Public Health (Approval Number 017-173/DD-YTCC).

\section{Consent for publication}

Not applicable.

\section{Competing interests}

The authors declare that they have no competing interests.

\section{Author details}

${ }^{1}$ Department of Health Management and Organization, Institute for Preventive Medicine and Public Health, Hanoi Medical University, 1A Ton That Tung Street, Dong Da District, 10000 Hanoi, Vietnam. ${ }^{2}$ Department of Hospital Management, Health Management Training Institute, Hanoi University of Public Health, 1A Duc Thang Road, Duc Thang Ward, North Tu Liem District, 10000 Hanoi, Vietnam.

Received: 23 September 2021 Accepted: 28 September 2021

Published: 28 January 2022

\section{References}

1. World Health Organization. Monitoring the building blocks of health systems: a handbook of indicators and their measurement strategies. Geneva: The WHO Document Production Services; 2010.

2. FIGO Safe Motherhood and Newborn Health Committee. Human resources for health in the low-resource world: collaborative practice and task shifting in maternal and neonatal care. Int J Gynaecol Obstet. 2009;105:74-6. https://doi.org/10.1016/j.ijgo.2008.11.007.

3. World Health Organization. Increasing access to health workers in remote and rural areas through improved retention Global policy recommendations. Geneva:WHO Press. 2010. https://apps.who.int/iris/handle/10665/ 44369. Accessed 1 Dec 2020.

4. World Health Organization. Workload Indicators of Staffing need (WISN): a Manual for Implementation. World Health Organization for Implementation. Division of Human Resources Development and Capacity Building, Geneva. 1998. https://apps.who.int/iris/handle/10665/64011. Accessed 1 Nov 2020. 
5. Okoroafor S, Ngobua S, Titus M, Opubo I. Applying the workload indicators of staffing needs method in determining frontline health workforce staffing for primary level facilities in Rivers state Nigeria. Glob Health Res Policy (BMC). 2019. https://doi.org/10.1186/s41256-019-0125-z.

6. Doosty F, Maleki MR, Yarmohammadian MH. An investigation on workload indicator of staffing need: a scoping review. J Educ Health Promot. 2019;8:22.

7. World Health Organization. Applying the WISN method in practice: Case study from Indonesia, Mozambique and Uganda. 2010. https://apps.who. int/iris/handle/10665/44415. Accessed 1 Dec 2020.

8. Vedanthan R, Lee DJ, Kamano JH, et al. Hypertension management in rural western Kenya: a needs-based health workforce estimation model. Hum Res Health. 2019;17(57):1-9.

9. Vietnamese Ministry of Health and Health Partnership Group. Joint annual health review: Human resources for health. Hanoi: 2009.

10. Vietnamese Ministry of Health. Joint Circular No.08/2007/TTLT-BYT-BNV stipulated staffing norms in the health facilities; 2007

11. World Health Organization. Workload indicators of staffing need-user's manual. World Health Organization, Geneva. 2010. https://www.who.int/ workforcealliance/knowledge/toolkit/17/en/. Accessed 10 Nov 2020.
12. Govule P, et al. Application of workload indicators of staffing needs (WISN) in determining health workers' requirements for Mityana General Hospital, Uganda. Int J Public Health Res. 2015;3(5):254-63.

13. Vietnam Government. Decree No. 106/2012/ND-CP defining the functions, tasks, powers and organizational structure; 2012

14. Rahmaniyah Dwi Astuti, Muhammad Abdu Haq Navi. Designing workload analysis questionnaire to evaluate needs of employees. The 3 rd International Conference on Industrial, Mechanical, Electrical, and Chemical Engineering 2018. p. 030027-1-8.

15. Namaganda G, Oketcho V, Maniple E, Viadro C. Making the transition to workload-based staffing: using the workload indicators of staffing need method in Uganda. Hum Res Health. 2015;13:89.

\section{Publisher's Note}

Springer Nature remains neutral with regard to jurisdictional claims in published maps and institutional affiliations.
Ready to submit your research? Choose BMC and benefit from:

- fast, convenient online submission

- thorough peer review by experienced researchers in your field

- rapid publication on acceptance

- support for research data, including large and complex data types

- gold Open Access which fosters wider collaboration and increased citations

- maximum visibility for your research: over $100 \mathrm{M}$ website views per year

At BMC, research is always in progress.

Learn more biomedcentral.com/submissions 